\title{
Mucormycosis - Life threatening invasive fungal disease
}

\author{
Review Article
}

\author{
Kavitha $\mathbf{J}^{1}$, Sivakrishnan $\mathbf{S}^{2 *}$, Lakshmisree $\mathbf{S}^{3}$, and Srinivasan $\mathbf{S}^{3}$ \\ 1. Associate Professor, Department of Periodontia, RMDCH, \\ 2. Assistant Professor, Department of Pharmacy, FEAT, \\ 3. Professor, Department of Periodontia, RMDCH, \\ Annamalai University, Annamalai Nagar, Chidambaram-608002, Tamilnadu, India.
}

\begin{abstract}
Mucormycosis, formerly known as zygomycosis, is a potentially fatal invasive fungal disease (IFD) caused by fungi in the Mucorales order and the zygomycetes class. Mucormycosis is a rare but deadly fungal infection that generally affects those who have weakened immune systems. The infection has the potential to spread throughout the body. Death is a possibility with this type of severe infection. It's important to get treatment. If left untreated, mucormycosis can be fatal. Zygomycosis has a high mortality of $70-100 \%$. The prevalence of mucormycosis in India is approximately 80 times that of developed countries, with 0.14 cases per 1000 population. The main aim and purpose of this review related to overview and history, causative agents, epidemiology, etiopathogenesis, transmission, types, clinical features, recent advances in diagnosis and treatment of Mucormycosis. A systematic literature search was conducted in the electronic databases of PubMed, Google Scholar and relevant sources. It will be helpful for those who work in the medicine field to explore their knowledge about mucormycosis.
\end{abstract}

Key Words: Mucormycosis, Immunity, Fungi, COVID-19, CT scan, Amphotericin B.

\section{Introduction}

Mucormycosis, also known as black fungus, is an uncommon but potentially fatal infection. It is caused by a type of mould known as mucormycetes and frequently affects the sinuses, lungs, skin, and brain. Mucormycosis is a rare but fatal fungal infection that typically affects patients with compromised immune systems. Mucormycosis is an angioinvasive disease caused by mould fungi of the genera Rhizopus, Mucor, Rhizomucor, Cunninghamella, and Absidia of the Order Mucorales, Class Zygomycetes (1). These fungi can be found in soil, bird and animal excretions, water and air near construction sites, moist environments, rotting food, and decaying organic matter such as leaves, compost piles, or rotten wood.

\section{History}

Mucormycosis was coined in 1957 by American pathologist R.D. Baker. Zygomycosis is another name for it. It is a sneaky fungal infection caused by members of the Mucorales and zygomycotic families. Mucormycotina are the most common

\section{* Corresponding Author:}

\section{Sivakrishnan S}

Assistant Professor,

Department of Pharmacy, FEAT,

Annamalai University, Annamalai Nagar,

Chidambaram-608002, Tamilnadu, India.

Email Id: sivacdm82@gmail.com saprobes found in rotten matter or soil. Mucorales infections are distinguished by their rapid progression (2). The most common type, Rhizopus Oryzae, is responsible for nearly $60 \%$ of mucormycosis cases in humans, as well as $90 \%$ of the Rhino-orbital-cerebral (ROCM) form (3). The inhalation of fungal spores is the mode of contamination.

Paltauf, a German pathologist, reported the first case of Mucormycosis in 1885 and named it Mycosis Mucorina $(4,5)$. Mucormycosis became more common among immunocompromised people in the 1980s and 1990s (6). A study conducted in France reported an amplification of $7.4 \%$ per year based on the prevalence rate (7). Mucorales infection has been reported to occur worldwide, with the possibility of seasonal variation (8).

\section{Causative agents}

Mucormycosis can be caused by a variety of fungi. Mucormycetes are fungi that belong to the scientific order Mucorales. The order Mucorales contains 261 species divided into 55 genera, 38 of which have been linked to human infections (9). Inhalation, ingestion, or direct inoculation allow fungal spores to enter the human body. The agents of mucormycosis differ depending on where you live. Rhizopus species (Rhizopus oryzae.) and Mucor species are the most common causes of mucormycosis (10). However, Apophysomyces, a family member found in tropical and subtropical climates, is the second most 
common in India. Apophysomyces and Saksenaea spp. are almost always the causative agents of cutaneous mucormycosis in immunocompetent patients, and they are mostly found in Asia $(11,12)$.

Other examples include Rhizomucor species, Syncephalastrum species, Cunninghamella bertholletiae, Apophysomyces, Cokeromyces, Actinomucor, Lichtheimia (formerly Absidia), Saksenaea, and Rhizomucor (13). New species are emerging, including Rhizopus homothallicus (14), Thamnostylum lucknowense (15), Mucor irregularis (16) and Saksenaea erythrospora (17). Their taxonomy has shifted dramatically in recent years as a result of molecular phylogenetic investigations, and some taxa have had many name revisions as a result. Table 1 shows the current nomenclature for these taxa.

Table 1. Current nomenclature of medically important mucoralean species according to updated taxonomy

\begin{tabular}{|l|l|}
\hline Previous Names/Synonyms & Current Species Names \\
\hline $\begin{array}{l}\text { Absidia corymbifera, } \\
\text { Mycocladus corymbifer }\end{array}$ & Lichtheimia corymbifera \\
\hline $\begin{array}{l}\text { Absidia ornate } \\
\text { Absidia ramosa, Mycocladus } \\
\text { ramosus }\end{array}$ & Lichtheimia ornata \\
\hline $\begin{array}{l}\text { Mucor ellipsoideus, Mucor } \\
\text { circinelloides f. circinelloides }\end{array}$ & Lichtheimia ramosa \\
\hline $\begin{array}{l}\text { Rhizomucor regularior, } \\
\text { Rhizomucor variabilis var. } \\
\text { regularior }\end{array}$ & Mucor circinelloides \\
\hline $\begin{array}{l}\text { Mucor circinelloides f. } \\
\text { griseocyanus }\end{array}$ & Mucor griseocyanus \\
\hline $\begin{array}{l}\text { Rhizomucor variabilis } \\
\text { junssenii circinelloides f. } \\
\text { Mucor circinelloides f. } \\
\text { lusitanicus }\end{array}$ & Mucor irregularis \\
\hline $\begin{array}{l}\text { Rhizopus oryzae } \\
\text { Rhizopus microsporus var. } \\
\text { azygosporus, var. chinensis, } \\
\text { var. oligosporus, var. } \\
\text { rhizopodiformis, var. tuberosus }\end{array}$ & Mucor janssenii \\
\hline & Rhizopus microsporus \\
\hline
\end{tabular}

\section{Reservoir}

Mucormycetes are moulds that are thermotolerant and can be found in nature. Mucormycetes are widely detected in soil, but are rarely identified in air samples aimed at fungal spores, according to environmental sampling studies (18). Environmental niches differ between genera and species. Inhalation, inoculation, or ingestion of spores from the environment are all methods of transmission (19-21).

\section{Types of mucormycosis}

Mucormycosis can also develop on the skin after the fungus enters the skin through a cut, scrape, burn, or other type of skin trauma. Types of mucormycosis are shown in Table 2.

\section{Table 2: Types of Mucormycosis}

Infection in the sinuses that can spread

Rhinocerebral (sinus and brain) mucormycosis

Pulmonary

(lung)

mucormycosis

Gastrointestinal mucormycosis

Cutaneous (skin) mucormycosis

Disseminated mucormycosis

\section{Epidemiology}

During 1992-1993, laboratory surveillance in the San Francisco Bay Area generated population-based mucormycosis incidence estimates, which revealed a yearly rate of 1.7 cases per 1 million persons (26). Mucormycosis was the third most prevalent invasive fungal infection among stem cell transplant recipients, accounting for $8 \%$ of all invasive fungal infections (77 mucormycete cases out of 983 stem cell transplant patients with any fungal infection) $(27,28)$. Mucormycosis was the third most common kind of invasive fungal infection among stem cell transplant recipients, accounting for $8 \%$ of all invasive fungal infections, according to prospective surveillance of 16,808 transplant recipients done in 23 institutions between 2001 and 2006. Mucormycosis accounted for $2 \%$ of all invasive fungal infections in solid organ transplant recipients (28 mucormycete cases out of 1,208 solid organ transplant recipients with any fungal infection) (29).

According to a recent estimate for the year 2019-2020 (30-32), the prevalence of mucormycosis ranged from 0.005 to 1.7 per million people worldwide, with a prevalence approximately 80 times greater $(0.14$ per 1000) in India than in industrialized countries. In other words, India has the world's highest rate of mucormycosis. Despite this, India has the world's second-largest diabetes mellitus (DM) population and was, until recently, the diabetes capital of the world (33). Importantly, in India, diabetes mellitus is the most common risk factor for mucormycosis, but in Europe and the United States, haematological malignancies and 
organ transplant take the lead. DM, however, remains the major risk factor for mucormycosis worldwide, with a 46 percent overall death rate (34).

Mucormycosis prevalence in France increased from 0.7 cases per million in 1997 to 1.2 cases per million in 2006, according to a nationwide populationbased study (35). Saegeman et al., from Belgium observed an increase from 0.019 cases per 10,000 patient days in 2000 to 0.148 cases per 10,000 patient days in 2009 (36). Mucormycosis is prevalent in India at a rate of 0.14 instances per 1000 people, which is almost 80 times higher than the rate in affluent countries (37). All of the preceding papers emphasise that mucormycosis is a new disease. The authors reported an increase in the percentage of documented cases by culture and decade. In the $1980 \mathrm{~s}$, the percentage was $50 \%$, and in the 2000 s, it was $71 \%$. This could indicate that, in addition to a real increase in the number of cases, better diagnostic tools or increased disease awareness are major factors. Chakrabarti et al. published three successive studies from a single location in India, finding that the incidence of mucormycosis was 12.9 cases/year during the first decade (38), 35.6 cases/year over a 5-year period, and 50 cases/year over an eighteen-month period (39).

\section{Mucormycosis outbreak}

Mucormycosis outbreaks have occurred, despite the fact that the majority of cases are sporadic (not part of an outbreak). In healthcare settings, determining whether mucormycosis is healthcare-associated or if the infections were acquired elsewhere might be difficult.

Multiple occurrences of healthcare-associated mucormycosis have been reported, either as isolated cases or outbreaks. 75 cases of mucormycosis were published in an Indian magazine over an eighteenmonth period, with 9 percent of them being nosocomial. Various exposures in the hospital environment have been linked to healthcare-associated mucormycosis (40-43):

- The most common cause of infection is the use of non-sterile items (44). Bandages, adhesives, nitroglycerin patches, contaminated linen (45), wooden tongue depressors, ostomy bags, and probiotics have all been linked to these infections. An outbreak linked to allopurinol tablets and packed food has even been reported.

- A variety of medical treatments and devices, such as catheters, insulin pumps, and finger sticks, as well as tube insertion, teeth extractions (46), and surgery.

- Infection can also be spread by environmental causes. Mould can be found in the air, dust, water, and on any surface in the hospital. Invasive fungal infections are more likely to occur during construction. Defective ventilation systems and water leakage have been connected to outbreaks.

Rammaert et al., found that $22 \%$ of the patients had diabetes, $24 \%$ had a solid organ transplant, $12 \%$ had a malignancy, $37 \%$ had a history of protracted steroid medication, and $5 \%$ had additional immunodepressive variables in their study of 169 cases.

Depending on the source of infection, the clinical presentation differs. The majority of infections caused by bandages, adhesives, or contaminated wound dressings are cutaneous in nature. Disseminated illness has resulted from percutaneous exposure in immunocompromised people. Inhalation causes pulmonary and rhino-cerebral infection, while gastrointestinal mucormycosis is caused by the absorption of tablets or food, as well as the use of tongue depressants. Peritonitis has been associated with dialysis catheters.

\section{Deaths due to mucormycosis}

Mucormycosis is a potentially fatal infection that affects a large number of people. According to a survey of confirmed mucormycosis patients, the allcause mortality rate is 54 percent (47). The fatality rate differed depending on the patient's underlying condition, the type of fungus, and the body part afflicted (for example, the mortality rate was 46 percent among people with sinus infections, 76 percent for pulmonary infections, and 96 percent for disseminated mucormycosis).

\section{Etiopathogenesis and Risk factors}

Mucorales attack deep tissues by ingesting or inhaling spores, as well as injecting spores into the skin. The initial line of defence in a healthy host is capable of killing spores via oxidative metabolites and cationic peptides as soon as the spores penetrate lung or skin tissues.

Mucormycosis is a contagious fungal infection. i.e., the "black fungus" infection cannot be passed from one person to another or between humans and animals. Inhaling spores, eating spores in food or medicine, or having spores contaminate wounds are the three ways humans might get mucormycosis.

The infection can happen to anyone at any age. Most people will come into contact with the fungus at some point in their everyday lives. Risk groups for mucormycosis include persons with:

$\begin{array}{ll}\checkmark & \text { Uncontrolled diabetes } \\ \checkmark & \text { HIV } \\ \checkmark & \text { Cancer } \\ \checkmark & \text { Organ transplant } \\ \checkmark & \text { Hematopoietic stem cell transplant } \\ \checkmark & \text { Persistent neutropenia } \\ \checkmark & \text { Prolonged corticosteroid therapy } \\ \checkmark & \text { Intravenous drug use } \\ \checkmark & \text { Hemochromatosis } \\ \checkmark & \text { Bad Health from Poor Nutrition } \\ \checkmark & \text { Metabolic acidosis } \\ \checkmark & \text { Skin trauma } \\ \checkmark & \text { Burns or Surgical Wounds } \\ \checkmark & \text { Iron overload } \\ \checkmark & \text { Premature birth or Low birth weight }\end{array}$

Mucormycosis develops as a damaging and sometimes fatal condition in diabetes individuals due to 
an increased availability of micronutrients and a weakening of the body's defence mechanisms (48). Several possibilities have been proposed, including: low serum inhibitory activity against Rhizopus species, increased availability of iron for the pathogen at lower $\mathrm{PH}$ levels, and pulmonary macrophages of diabetics have a reduced ability to prevent Rhizopus species germination. Rhizopus has a ketone reductase enzyme that permits it to boost its glucose and acidic environment.

All kinds of mucormycosis can occur in DM, especially when ketoacidosis is present $(49,50)$. Neutrophils are important in the host's defence against mucorales. In diabetic mellitus, its function is reduced at several levels. Diabetes-related ketoacidosis hastens fungal invasion. The low level of dialyzable inhibitory factor in diabetics, along with an acidic environment that releases more free iron by lowering its binding to transferrin, creates ideal circumstances for fungal replication. Before the introduction of amphotericin B and extensive surgery, Mucormycosis had a reported mortality rate of $90 \%$ or even higher. Mucormycosis is more common in severely neutropenic patients and those who lack phagocytic activity. In the case of AIDS patients, however, this is not the case. It implies that only neutrophils, not $\mathrm{T}$ lymphocytes, are important in preventing fungal proliferation. Patients with haematological malignancies and hematopoietic stem cell transplants are more likely to develop mucormycosis after receiving long-term voriconazole treatment $(51,52)$. Mucormycosis can also be found in people who don't seem to have a problem with their immune system. It's possible that it's linked to burns, trauma, or iatrogenic elements in such cases (53).

Covid-19 infections are more severe in people with diabetes and obesity. This increases their chances of receiving corticosteroids, which are commonly used to treat Covid-19. However, corticosteroids, in combination with diabetes, raise the risk of mucormycosis. Meanwhile, the virus that causes Covid-19 can harm airway tissue and blood vessels, putting them at risk of fungal infection. So, tissue and blood vessel damage from Covid-19 infection, corticosteroid treatment, high background rates of diabetes in the population most severely affected by the coronavirus, and, most importantly, more widespread exposure to the fungus in the environment are all likely to be contributing to the mucormycosis situation seeing in India. Several occurrences of mucormycosis have been documented in India among Covid-19 recovered and recovering patients, resulting in blindness or other significant complications. Surat, Gujarat, Delhi, and Maharashtra have all reported cases of mucormycosis. The mucormycosis infection caused by Covid-19 is treatable, but if left untreated or addressed late, the rare infection can cause eyesight loss and, in certain cases, raise the chance of death. Furthermore, COVID patients receiving oxygen therapy in an ICU with a humidifier are susceptible to fungal infection due to moisture exposure. However, this does not rule out the possibility of Mucormycosis infection in COVID patients.
Although the disease is rare in those who do not have diabetes, it can be lethal if not treated swiftly.

\section{Clinical features}

Mucormycosis symptoms vary depending on where the fungus is developing in the body. $(54,55)$ Mucormycosis has five major clinical manifestations, the most prevalent of which are rhinocerebral and pulmonary infections. The quick onset of tissue necrosis with or without fever is a hallmark clinical indication of mucormycosis. The invasion of blood vessels and subsequent thrombosis causes necrosis. Table 3 shows the clinical features of mucormycosis types.

Table 3: Clinical features of Mucormycosis types Mucormycosis Types

\section{Clinical Features}

The most prevalent kind in diabetics and those who have had a kidney transplant. It also affects neutropenic cancer patients, as well as those who have received a hematopoietic stem cell transplant or a solid organ transplant.
Rhinocerebral (sinus and brain) mucormycosis

Pulmonary

(lung) mucormycosis

Cutaneous

(skin)

mucormycosis Symptoms include unilateral face swelling, headaches, nasal or sinus congestion or pain, serosanguinous nasal discharge, and fever. As the infection progresses, ptosis, proptosis, loss of extraocular muscle function, and vision impairment may result. Necrotic black lesions on the hard palate or nasal turbinate, as well as drainage of black pus from the eyes, are diagnostic indicators.

Generally, it occurs in patients with hematologic malignancy or profound neutropenia. Fever, cough, chest pain, and dyspnea are some of the nonspecific symptoms. Tissue necrosis occurs as a result of angioinvasion, which can lead to cavitation and/or hemoptysis.

It may be primary or secondary. Primary infection is caused by the fungus directly inoculating itself into disturbed skin. It is most commonly seen in patients with burns or other forms of local skin trauma, although it can also happen in patients who are not immunocompromised. Initial infection causes pus, abscess formation, tissue swelling, and necrosis, as well as an acute inflammatory response. The lesions might be red and indurated, and they frequently turn into black eschars. When a pathogen spreads hematogenously, secondary cutaneous infection occurs; lesions typically begin as an erythematous, indurated, and painful cellulitis and proceed to an ulcer covered in a black eschar. 
It is less prevalent than the other clinical types and is thought to be caused by the organism being consumed. It usually affects malnourished people or premature babies. Most typically, the stomach, colon, and ileum are impacted.

Gastrointestinal The most common symptoms include nonspecific abdominal pain and distension, nausea, and vomiting, as well as gastrointestinal bleeding. It's the most frequent type of mucormycosis in newborns, and it's difficult to diagnose since it looks like necrotizing enterocolitis, a far more common disease.

Usually affects people who are already sick from other medical diseases. Determining which symptoms are attributable to mucormycosis can be challenging. Dis se minated Disseminated mucormycosis can occur after any of the mucormycosis previous types of mucormycosis, but it's most common in neutropenic patients with a lung infection. The brain is the most common location of spread, but it can also affect the spleen, heart, skin, and other organs.

\section{Diagnosis}

Diagnosis and intervention as early as possible are important. This comprises blood sugar control, the removal of dead tissue as soon as possible, and antifungal medicine treatment. However, many infections will be detected late, and treatment options will be limited. Prior to Covid-19, this was the case in India, and the current strains on the health system will only exacerbate the situation. Controlling these fungal infections would necessitate improved awareness, better testing to detect them early, as well as an emphasis on diabetes management and the prudent use of corticosteroids. Patients will need access to surgery and antifungal treatment as soon as possible. However, more research into the prevention of these illnesses is required.

Mucormycetes can be difficult to distinguish from other filamentous fungi in tissue, hence expert pathological and microbiological expertise is frequently required. There are currently no regular serologic diagnostics for mucormycosis, and blood tests like betaD-glucan or Aspergillus galactomannan do not detect mucormycetes. Although DNA-based detection approaches show promise, they are not yet fully standardised or commercially available. Mucormycosis diagnosis entails a careful examination of clinical manifestations, magnetic resonance imaging modalities, early-stage computed tomography (CT), expert assessment of cytological and histological provision, best use of clinical microbiological approach, and molecular detection. Histopathological evidence or a positive culture from a specimen taken from the infection site are usually required for a conclusive diagnosis of mucormycosis. In comparison to colonisation, specimens from sterile body locations provide stronger evidence of invasive infection (56). In individuals with infection that is clinically consistent with mucormycosis, culture of non-sterile locations (e.g., sputum) may be beneficial. The detection of host variables is crucial in determining if a patient is at risk for invasive mucormycosis. The numerous laboratory procedures for identifying mucor include PAS stains, direct examination, calcofluor, histological examination, Gomori methenamine silver stain, culture, molecular approaches, and fluorescent in situ hybridization. According to Kontoyiannis et al., one of the most difficult aspects of identifying mucormycosis is its indefinable clinical presentation and repeated occult spread, necessitating the use of a sensitive nonculturebased investigative method. Tissue-based analysis is the gold standard analytic technique for confirmation (57). Mucormycosis can be distinguished by the presence of maxillary sinus neoplasia, aspergillosis of the maxillary sinus, soft tissue infarction, soft tissue radio necrosis, and other deep fungal infections.

\section{Treatment}

Although the infection may start as a skin infection, it has the potential to spread to other places of the body. Surgical removal of all dead and diseased tissue is required for treatment. This can lead to the loss of the upper jaw or possibly the eye in some people. A 4-6-week course of intravenous antifungal medication may also be required to cure the infection. Treatment needs a team of microbiologists, internal medicine specialists, intensivist neurologists, ENT specialists, ophthalmologists, dentists, surgeons, and others because it affects numerous sections of the body.

Mucormycosis does not have a vaccination. For patients with mucormycosis, early detection, diagnosis, and timely administration of effective antifungal treatment are critical to improve outcomes (58).

The first steps in treating mucormycosis are intravenous antifungal medications and surgical debridement. Surgical debridement is the process of surgically eliminating all unhealthy tissue from the body. It has been established that eliminating diseased tissue prevents the infection from spreading.

\section{Common antifungal medications for Mucormycosis}

Most mucormycetes are resistant to amphotericin B (IV), Posaconazole (IV or orally), and Isavuconazole (IV or orally). Amphotericin B lipid formulations are frequently utilised as a first-line therapy. Voriconazole, which is used to treat Aspergillus, is not effective against mucormycetes, and there is some evidence that pre-exposure to voriconazole may be linked to an increased risk of mucormycosis in some patients (59). Surgical debridement or removal of contaminated tissue is also frequently required, especially for rhinocerebral, cutaneous, and gastrointestinal infections. When possible, control of the underlying immunocompromising disease should be addressed (60). Other therapies, such as hyperbaric oxygen therapy, have been shown to be effective in specific cases. Rapid accurate diagnosis, surgical debridement, and medicine administration, as well as adjuvant 
application of hyperbaric oxygen, recombinant cytokines, or transfusion of granulocytes and prosthetic obturator, are all effective treatments for mucormycosis.

Spellberg et al., claim that currently available monotherapy has a high mortality rate, particularly in haematology patients, and so recommend "combination therapy" for Mucormycosis (61).

Amphotericin B Dexycholate, Liposomal Amphotericin B $(5-10 \mathrm{mg} / \mathrm{kg})$, Amphotericin B lipid complex, Amphotericin B colloidal dispersion, Posaconazole (400mg daily), and management of core conditions are examples of antifungal medicines. Second-line therapy options include caspofungin and lipid Amphotericin B, or a combination of lipid Amphotericin B and Posaconazole, but not Deferasirox.

In the case of soft tissues, surgical treatment should be considered for cerebral disseminated, localized pulmonary lesions, and rhino-orbito-types.

\section{Lower the risk of Mucormycosis}

$\checkmark$ Because the fungi that cause mucormycosis are ubiquitous in the environment, it is difficult to avoid breathing in fungal spores. Mucormycosis can't be prevented with a vaccine. For people with weakened immune systems, there may be some measures to lower their chance of contracting mucormycosis.

$\checkmark$ Protect yourself from the effects of the environment. It's important to keep in mind that, while these suggestions are helpful, they haven't been proven to prevent mucormycosis.

$\checkmark$ Avoid places with a lot of dust, such as construction and excavation sites. If you can't avoid being in these places, put on a N95 respirator (a type of face mask).

$\checkmark$ Stay away from water-damaged structures and flood water after storms and natural disasters.

$\checkmark$ Avoid tasks that involve close contact with soil or dust, such as yard maintenance or gardening.

$\checkmark$ Wear shoes, long pants, and a long-sleeved shirt when doing outdoor tasks like gardening, yard care, or visiting woodland areas.

$\checkmark$ When working with items like soil, moss, or manure, use gloves.

$\checkmark$ To reduce the risk of infection, carefully clean skin injuries with soap and water, especially if they have been exposed to soil or dust.

\section{Conclusion}

Mucormycosis is a life-threatening fungal illness that affects people who are immunocompromised or diabetic. It reveals a high and worrisome death rate. Despite treatment, death continues to be a problem. Although early detection and treatment can result in improved outcomes, the total death rate is around $50 \%$. The current state of mucormycosis is discussed in this review. Mucormycosis does not have a vaccination. Keep yourself safe from the surroundings. It seems to be worth noting that, while these steps are suggested, they have not yet been shown to prevent mucormycosis. In order to recover from the predisposing variables, you must first identify them. Early detection, diagnosis, surgical debridement, and quick administration of appropriate antifungal medication, such as first-line therapy with liposomal amphotericin B paired with surgery wherever possible, are all important. Isavuconazole and intravenous or delayed-release tablet versions of posaconazole have remained second-line therapy for mucormycosis patients, and they are helpful for lowering risks and improving results.

\section{References}

1. Farmakiotis D, Kontoyiannis DP. Mucormycoses. Infectious Disease Clinics of North America. 2016; 30(1):143-63.

2. Kwon-Chung KJ. Taxonomy of fungi causing mucormycosis and entomophthoramycosis (zygomycosis) and nomenclature of the disease: molecular mycologic perspectives. Clinical Infectious Diseases. 2012; 54(1): S8-15.

3. Sugar A.M. In: Mandell, Douglas, and Bennett's principles and practice of infectious diseases. fifth ed. Mandell G.L., Bennett J.E., Dolin R., editors. Churchill Livingstone; New York, USA: 2000.

4. Mohammadi R, Nazeri M, Sayedayn SM, Ehteram H. A successful treatment of rhinocerebral mucormycosis due to Rhizopus oryzae. Journal of research in medical sciences: The Official Journal of Isfahan University of Medical Sciences, 2014; 19(1): 72 .

5. Ramalingam Suganya, Narasimhan Malathi, Vinithra Karthikeyan and Vyshnavi, Devi Janagaraj. Mucormycosis: A Brief Review. Journal of Pure and Applied Microbiology. 2019; 13(1):161-165.

6. Roden MM, Zaoutis TE, Buchanan WL, Knudsen TA, Sarkisova TA, Schaufele RL, Sein M, Sein T, Chiou CC, Chu JH, Kontoyiannis DP. Epidemiology and outcome of zygomycosis: A review of 929 reported cases. Clinical Infectious Diseases. 2005; 41(5): 634-53.

7. Bitar D, Van Cauteren D, Lanternier $\mathrm{F}$ et al., Increasing incidence of zygomycosis (mucormycosis), France, 1997-2006. Emerging Infectious Diseases Journal. 2009; 15(9): 1395-401.

8. Petrikkos G, Skiada A, Lortholary O, Roilides E, Walsh TJ, Kontoyiannis DP. Epidemiology and clinical manifestations of mucormycosis. Clinical Infectious Diseases. 2012; 54(1): S23-34.

9. Walther G, Wagner L, Kurzai O. Updates on the Taxonomy of Mucorales with an Emphasis on Clinicallv Important Taxa. Journal of Fungi. 2019; 5(4):106.

10. Roden MM, Zaoutis TE, Buchanan WL, Knudsen TA, Sarkisova TA, Schaufele RL, et al., Epidemiology and outcome of zygomycosis: A review of 929 reported cases external icon. Clinical Infectious Disease. 2005; 41(5):634-53.

11. Prakash H, Ghosh A, Rudramurthy S, Paul R, Gupta S, Negi V, Chakrabarti A. The environmental source of emerging Apophysomyces variabilis infection in India. Medical Mycology Journal. 2016; 54(6): 567-575.

12. Chakrabarti A, Singh R. Mucormycosis in India: Unique features. Mycoses: Special Issue: Zygomycetes: An emerging Problem in the Clinical Laboratory. 2014; 57 (3): 85-90. 
13. Al-Ajam, MR, Bizri, AR, Mokhbat, J, Weedon, J, Lutwick, L. Mucormycosis in the Eastern Mediterranean: a seasonal disease external icon. Epidemiology and Infection. 2006; 134(2):341-6.

14. Chakrabarti A, Marak R.S.K, Shivaprakash M.R, Gupta S, Garg R, Sakhuja V, et al., Cavitary Pulmonary Zygomycosis Caused by Rhizopus homothallicus. Journal of Clinical Microbiology. 2010; 48(5):1965-69. [CrossRef]

15. Xess I, Mohapatra S, Shivaprakash M.R, Chakrabarti A, Benny G.L, O’Donnell K, Padhye A.A. Evidence Implicating Thamnostylum lucknowense as an Etiological Agent of RhinoOrbital Mucormycosis. Journal of Clinical Microbiology. 2012; 50(4): 1491-94.

16. Lu X.-L, Najafzadeh M, Dolatabadi S, Ran Y.-P, Ende A.G.V.D, Shen Y.-N et al., Taxonomy and epidemiology of Mucor irregularis, agent of chronic cutaneous mucormycosis. Persoonia - Molecular Phylogeny and Evolution of Fungi. 2013; 30: 4856.

17. Chander J, Singla N, Kaur M, Punia R.S, Attri A, Alastruey-Izquierdo A et al., Saksenaea erythrospora, an emerging mucoralean fungus causing severe necrotizing skin and soft tissue infections - A study from a tertiary care hospital in north India. Journal of Infectious Diseases. 2017; 49:170-177.

18. Ziaee A, Zia M, Bayat M, Hashemi. Identification of Mucorales isolates from soil using morphological and molecular methods external icon. Current Medical Mycology. 2016; 2(1):13-19.

19. Rammaert B, Lanternier F, Zahar JR, Dannaoui E, Bougnoux ME, Lecuit $\mathrm{M}$, et al., Healthcareassociated mucormycosis external icon. Clinical Infectious Diseases. 2012; 54 (1): S44-54.

20. Duffy J, Harris J, Gade L, Sehulster L, Newhouse $\mathrm{E}$, O'Connell $\mathrm{H}$, et al., Mucormycosis outbreak associated with hospital linens external icon. Pediatric Infectious Disease Journal. 2014; 33(5):472-6.

21. Novosad SA, Vasquez AM, Nambiar A, Matthew AJ, Christensen E, Moulton-Meissner $\mathrm{H}$, et al. Notes from the field: probable mucormycosis among adult solid organ transplant recipients at an acute care hospital-Pennsylvania, 2014-2015. Morbidity and Mortality Weekly Report. 2016; 65(18):481-82.

22. Dadwal SS, Kontoyjannis DP. Recent advances in the molecular diagnosis of mucormycosis external icon. Expert Review of Molecular Diagnostics. 2018; 18(10):845-854.

23. Song Y, Qiao J, Giovanni G, Liu G, Yang H, Wu J, Chen J. Mucormycosis in renal transplant recipients: review of 174 reported cases external icon. BMC Infectious Diseases. 2017; 17(1): 283;

24. Abdalla A, Adelmann D, Fahal A, Verbrugh H, Van Belkum A, De Hoog S. Environmental occurrence of Madurella mycetomatis, the major agent of human eumycetoma in Sudan external icon. Journal of Clinical Microbiology. 2002; 40(3): 1031-1036.
25. Francis JR, Villanueva P, Bryant P, Blyth CC. Mucormycosis in children: review and recommendations for management external icon. Journal of Pediatric Infectious Diseases Society. 2018; 7(2):159-164.

26. Rees JR, Pinner RW, Hajjeh RA, Brandt ME, Reingold AL. The epidemiological features of invasive mycotic infections in the San Francisco Bay area, 1992-1993: results of population-based laboratory active surveillance external icon. Clinical Infectious Diseases. 1998; 27(5):1138-47.

27. Kontoyiannis DP, Marr KA, Park BJ, Alexander $\mathrm{BD}$, Anaissie EJ, Walsh TJ, et al., Prospective surveillance for invasive fungal infections in hematopoietic stem cell transplant recipients, 2001-2006: overview of the Transplant-Associated Infection Surveillance Network (TRANSNET) Database external icon. Clinical Infectious Diseases. 2010; 50(8):1091-100.

28. Park BJ, Pappas PG, Wannemuehler KA, Alexander $\mathrm{BD}$, Anaissie EJ, Andes DR, et al., Invasive nonAspergillus mold infections in transplant recipients, United States, 2001-2006 external icon. Emerging Infectious Diseases. 2011; 17(10):1855-64.

29. Pappas PG, Alexander BD, Andes DR, Hadley S, Kauffman CA, Freifeld A, et al., Invasive fungal infections among organ transplant recipients: results of the Transplant-Associated Infection Surveillance Network (TRANSNET)external icon. Clinical Infectious Diseases. 2010; 50(8):1101-11.

30. Skiada A, Pavleas I, Drogari-Apiranthitou M. Epidemiology and diagnosis of mucormycosis: An Update. Journal of Fungi. 2020; 6(4):265.

31. Chander J, Kaur M, Singla N. Mucormycosis: Battle with the deadly enemy over a five-year period in India. Journal of Fungi. 2018; 4(2):46.

32. Prakash H., Chakrabarti A. Global epidemiology of mucormycosis. Journal of Fungi. 2019; 5(1):26.

33. International Diabetes Federation IDF diabetes atlas. 2019. https://diabetesatlas.org/en/resources/

34. Jeong W, Keighley C, Wolfe R. The epidemiology and clinical manifestations of mucormycosis: A systematic review and meta-analysis of case reports. Clinical Microbiology and Infection. 2019; 25(1):26-34.

35. Lanternier F, Dannaoui E, Morizot G, Elie C, Garcia-Hermoso D, Huerre M, et al., The French Mycosis Study Group. A Global Analysis of Mucormycosis in France: The RetroZygo Study (2005-2007). Clinical Infectious Diseases. 2012; 54(1): S35-S43.

36. Saegeman V, Maertens J, Meersseman W, Spriet I, Verbeken E, Lagrou K. Increasing Incidence of Mucormycosis in University Hospital, Belgium. Emerging Infectious Diseases. 2010; 16(9):14561458.

37. Chander J, Singla N, Kaur M, Punia R.S, Attri A, Alastruey-Izquierdo A, et al., Saksenaea erythrospora, an emerging mucoralean fungus causing severe necrotizing skin and soft tissue infections - A study from a tertiary care hospital in 
north India. Infectious Diseases. 2017; 49(3):170 177.

38. Chakrabarti A, Das A, Sharma A, Panda N, Das S, Gupta K, Sakhuja V. Ten Years' Experience in Zygomycosis at a Tertiary Care Centre in India. Journal of Infection. 2001; 42(4): 261-266.

39. Chakrabarti A, Chatterjee S.S, Das A, Panda N, Shivaprakash M.R, Kaur A, et al., Invasive zygomycosis in India: Experience in a tertiary care hospital. Postgraduate Medical Journal. 2009; 85(1009):573-581.

40. Neblett Fanfair R, Benedict K, Bos J, Bennett SD, Lo YC, Adebanjo T, et al., Necrotizing cutaneous mucormycosis after a tornado in Joplin, Missouri, in 2011external icon. New England Journal of Medicine. 2012; 367(23):2214-25.

41. Novosad SA, Vasquez AM, Nambiar A, Matthew AJ, Christensen E, Moulton-Meissner $\mathrm{H}$, et al., Notes from the field: probable mucormycosis among adult solid organ transplant recipients at an acute care hospital -Pennsylvania, 2014-2015. Morbidity and mortality weekly report. 2016; 65(18):481-482.

42. Chaves MS, Franco D, Nanni JC, Basaldúa ML, Boleas M, Aphalo G et al., Control of an outbreak of postoperative bone mucormycosis: An intervention study of contiguous cohorts' external icon. American Journal of Infection Control. 2016; 44(12):1715-1717.

43. Rammaert B, Lanternier F, Zahar J.-R, Dannaoui E, Bougnoux M.-E, Lecuit M, Lortholary O. Healthcare-associated mucormycosis. Clinical Infectious Diseases. 2012; 54 (1): S44-S54.

44. Hartnett K.P, Jackson B.R, Perkins K.M, Glowicz J, Kerins J.L, Black S.R, Lockhart S.R, et al., A Guide to Investigating Suspected Outbreaks of Mucormycosis in Healthcare. Journal of Fungi. 2019; 5(3): 69 .

45. Duy J, Harris J, Gade L, Sehulster L, Newhouse E, O'Connell $\mathrm{H}$ et al., Mucormycosis Outbreak Associated with Hospital Linens. Pediatric Infectious Disease Journal. 2014; 33(5): 472-476.

46. Prabhu S, Alqahtani M, Al Shehabi M. A fatal case of rhinocerebral mucormycosis of the jaw after dental extractions and review of literature. Journal of Infection and Public Health. 2018; 11(3): 301303.

47. Roden MM, Zaoutis TE, Buchanan WL, Knudsen TA, Sarkisova TA, Schaufele RL, et al., Epidemiology and outcome of zygomycosis: A review of 929 reported cases external icon. Clinical Infectious Diseases. 2005;41(5):634-53.

48. Rammaert B, Lanternier F, Poire S, Kania R, Lortholary O. Diabetes and mucormycosis: A complex interplay. Diabetes \& metabolism, 2012; 38(3): 193-204.
49. Bhansali A, Sharma A, Kashyap A, Gupta A, Dash RJ. Mucor endophthalmitis. Acta ophthalmologica Scandinavica. 2001; 79(1):88- 90.

50. Tsaousis G, Koutsouri A, Gatsiou C, Paniara O, Peppas C, Chalevelakis G. Liver and brain mucormycosis in a diabetic patient type II successfully treated with liposomal amphotericin B. Scandinavian journal of infectious diseases. 2000; 32(3): 335- 7.

51. Wingard JR, Carter SL, Walsh TJ, et al. Randomized, double-blind trial of fluconazole versus voriconazole for prevention of invasivefungal infection after allogeneic hematopoietic cell transplantation. Blood. 2010; 116: 5111-18.

52. Marks DI, Pagliuca A, Kibbler CC, et al. Voriconazole versus itraconazole for antifungal prophylaxis following allogeneic haematopoietic stem-cell transplantation. British Journal of Haematology. 2011; 155(3): 318-27.

53. Skiada A, Petrikkos G. Cutaneous mucormycosis. Clinical microbiology and infection. 2009; 15(5): 41-5.

54. Cheng VC, Chan JF, Ngan AH, et al., Outbreak of intestinal infection due to Rhizopus microsporus. J. Clin. Microbiol., 2009; 47(9): 2834-43.

55. Kontoyiannis $\mathrm{P}$, Lewis RE. How I treat mucormycosis external icon. Blood. 2011;118(5):1216-24.

56. Kontoyiannis DP, Lionakis MS, Lewis $\mathrm{RE}$, et al., Zygomycoses in a teritary-care cancer center in the era of Aspergillus-active antifungaltherapy: a case-control observational study of 27 recent cases. Journal of Infectious Diseases. 2005; 191:1350-60

57. Petrikkos G, Skiada A, Lortholary O, Roilides E, Walsh TJ, Kontoyiannis DP. Epidemiology and clinical manifestations of mucormycosis external icon. Clinical Infectious Diseases. 2012; 54 (1): S23-34.

58. Dadwal SS, Kontoyjannis DP. Recent advances in the molecular diagnosis of mucormycosis external icon. Expert Rev of Mol Diagn. 2018 Oct; 18(10):845-854.

59. Song Y, Qiao J, Giovanni G, Liu G, Yang H, Wu J, Chen J. Mucormycosis in renal transplant recipients: review of 174 reported cases external icon. BMC Infectious Diseases. 2017;17(1): 283.

60. Lewis RE, Kontoyiannis DP. Epidemiology and treatment of mucormycosis external icon. Future Microbiology. 2013; 8(9):1163-75.

61. Brad Spellberg, Ashraf Ibrahim, Emmanuel Roilides, Russel E. Lewis, Olivier Lortholary, George Petrikkos, et al., Walsh. Combination Therapy for Mucormycosis: Why, what, and how? Clinical Infectious Diseases. 2012; 54(1): S73-S78. 